\title{
Effect of Tryptophan Treatment on Self-Biting and Central Nervous System Serotonin Metabolism in Rhesus Monkeys (Macaca mulatta)
}

\author{
Katherine P. Weld, Ph.D., Joy A. Mench, Ph.D., Ruth A. Woodward, D.V.M., \\ Monica S. Bolesta, Ph.D., Stephen J. Suomi, Ph.D., and J. Dee Higley
}

\begin{abstract}
Two studies were conducted to examine the effects of oral L-tryptophan (TRP) supplementation as a treatment for self-injurious behavior (SIB) and to investigate behavior and central serotonin turnover of male rhesus monkeys. In Study One, TRP was administered to seven individually housed rhesus monkeys with a recent history of spontaneous SIB. While the monkeys were on TRP treatment $(100 \mathrm{mg} / \mathrm{kg}$ twice a day), cisternal cerebrospinal fluid (CSF) concentrations of 5-hydroxyindoleacetic acid increased markedly $(\mathrm{p}=.0013)$ above baseline (baseline mean $=$ $207.6 \mathrm{pmol} / \mathrm{ml} \pm 39 ; \mathrm{TRP}$ mean $=320.3 \mathrm{pmol} / \mathrm{ml} \pm 83.4$ ), and the duration of self-biting behavior decreased below
\end{abstract}

baseline ( $\mathrm{p}=.03)$. In Study Two, 14 individually housed rhesus monkeys without a history of SIB were placed on three different doses of TRP in random order $(50,100$, and $200 \mathrm{mg} / \mathrm{kg}$ twice a day). TRP had no effect on any behavioral or biochemical variables in the normal monkeys. Conclusions: Supplemental tryptophan in well-tolerated doses reduced self-biting and increases serotonin turnover rate in male monkeys with a recent history of SIB. The same doses of TRP do not affect behavior or serotonin metabolism in male monkeys without a history of SIB.

[Neuropsychopharmacology 19:314-321, 1998]

Published by Elsevier Science Inc.
KEY WORDS: L-Tryptophan; Behavior; Cerebrospinal fluid; 5-Hydroxyindoleacetic acid; Macaca mulatta; Serotonin

Self-injurious behavior (SIB) occurs in humans (reviewed by Winchel and Stanely 1991; Favazza and Rosenthal 1993) and other species (see Meyer-Holzapfel

From the University of Maryland (KPW, MSB), College Park, Maryland; Laboratory of Clinical Studies/DICBR/NIAAA (KPW, JDH), National Institutes of Health, Poolesville, Maryland; University of California (JAM), Davis, California; Advanced BioScience Laboratories, Incorporated (RAW), Rockville, Maryland; and Laboratory of Comparative Ethology/NICHD (SJS), National Institutes of Health, Bethesda, Maryland, USA.

Address correspondence to: Katherine P. Weld, Ph.D., National Institutes of Health Animal Center, P. O. Box 529, Poolesville, MD 20837, USA.

Received July 22, 1997; revised January 12, 1998; accepted January 28,1998 .
1968; Jones and Barraclough 1978). In humans, SIB has been described as representing a continuum of behavior ranging from occasional noninjurious biting, scratching, and head banging to persistent self-biting and cutting associated with severe physical injuries (Harris 1995; Walsh and Rosen 1988). SIB also occurs in rhesus monkeys, most often as a result of self-biting (Tinklepaugh 1928; Erwin et al. 1973; Capitanio 1986). A retrospective study documenting the incidence of wounding in three primate colonies (Bayne et al. 1995) showed that, of 253 monkeys studied, $0.8 \%$ engaged in self-injurious behavior that resulted in wounds requiring veterinary treatment. Although severe self-biting in nonhuman primates is a relatively uncommon phenomenon, it nevertheless remains a serious concern, because it can lead to severe and sometimes fatal injuries. 
Neuroleptics, anxiolytics, sedative-hypnotics, stimulants, antidepressants and mood stabilizers, anticonvulsants, behavior modification, antihypertensives and opiate antagonists have all been used as treatments for SIB with varying degrees of success. Recent reviews conclude that there is no single, universally accepted treatment for SIB (Harris 1995; Luchins 1990). In addition, there is evidence that effective doses of most medications used to treat SIB have unacceptable side effects (see review by Osman and Loschen 1992).

Serotonin (5-HT), is believed to be involved in the regulation of many behaviors including aggression, arousal, pain sensitivity, and irritability (Brown et al. 1979; Valzelli and Bernasconi 1979; Cleare and Bond 1995), and could theoretically play a role in SIB. If SIB, indeed, results from misdirected aggression, hyper- or hypoarousal, and/or reduced pain sensitivity, modifying the functioning of the serotonergic system might be expected to alter such SIB-related behaviors as selfdirected aggression. Low central nervous system (CNS) 5-HT turnover rate, as measured by low cerebrospinal fluid (CSF) concentrations of the major metabolite of 5-HT, 5-hydroxyindoleacetic acid (5-HIAA) in CSF, has been observed to be correlated with high levels of aggression in both humans and nonhuman primates (Brown et al. 1979; Linnoila et al. 1983; Roy and Linnoila 1988; Roy et al. 1988; Higley et al. 1996). Pharmacological reduction of the availability of 5-HT and its precursors increases aggressive behaviors (Chamberlain et al. 1987; Young et al. 1989). Conversely, pharmacologically increasing availability of 5-HT and its precursors results in reduced rates of aggression (Lindgren and Kantak 1987; Raleigh 1987; Shea et al. 1990; see review by Olivier et al. 1991). Some patients who exhibit selfaggressivity have low CSF 5-HIAA concentrations (Lopez-Ibor et al. 1985). If SIB is thought of as aggression turned toward oneself, it is possible that increasing CNS 5-HT function could decrease or eliminate SIB.

One method for increasing CNS 5-HT functioning is to increase the availability of its precursor, tryptophan (TRP). TRP has been used successfully to increase 5-HT synthesis in a wide range of species under a variety of conditions (Pardridge 1977; Gillman et al. 1981; Chamberlain et al. 1987; Young et al. 1989; Shea et al. 1991; Mench and Shea-Moore 1995). Given these findings, we hypothesized that TRP supplementation would: (1) increase central 5-HT turnover and decrease self-biting in rhesus monkeys with a history of SIB; and (2) in normal (nonSIB) individually housed rhesus monkeys, increased central 5-HT turnover would lead to changes in their behavioral repertoires. To the best of our knowledge, no one to date has specifically examined the physiological and behavioral responses of SIB and normal individually housed rhesus monkeys to oral TRP treatment.

Two studies were performed to test these hypotheses. In both studies, the amount of TRP in the normal and SIB monkeys' diets was increased by offering them flavored treats supplemented with TRP. This method for administering TRP is both unobtrusive and provokes minimal stress responses in the subject. CSF 5-HIAA and behaviors of the monkeys were measured at regular intervals throughout the studies. Because TRP loading has been associated with a reduction in availability of the catecholamines' precursor (Huether et al. 1992), and because 5-HT interacts with CNS norepinephrine system (Raleigh 1987), changes in CNS concentrations of the major metabolites of norepinephrine and dopamine were also monitored to determine any possible effect that TRP might have on the catecholamine turnover rates in the SIB and normal monkeys.

\section{METHODS}

\section{Study One: Self-Injuring Monkeys}

Subjects. The subjects were selected by requesting rhesus monkeys with a history of spontaneous SIB from 14 primate veterinarians with access to large nonhuman primate populations. Over a 2-year period, nine individually housed male rhesus monkeys were identified as having a recent history of developing SIB of sufficient severity to require veterinary attention (i.e., suturing). The monkey's background information (surgical and/or research history) was screened to determine if any procedures had been conducted that would preclude using the monkey in the study (e.g., brain lesioning or castration). Two subjects were rejected as a result of this criterion leaving a sample size of seven individuals. One goal of the study was to treat the SIB monkeys without adding such a stressor as relocation to unfamiliar surroundings. Therefore, TRP was administered to each individual in its familiar home-cage setting. All research was carried out under NIH guidelines, using an approved animal study protocol.

\section{Study Design}

There were three phases to the study: (1) a 1-week placebo baseline; (2) a 21-day treatment period; and (3) a 1-week placebo posttest. During baseline and posttest, placebo was administered twice a day in the same fashion as during the treatment phase. During the treatment period (phase 2), the monkeys received TRP orally twice a day at a dose of $100 \mathrm{mg} / \mathrm{kg}$ in flavored, commercially available primate treats. The morning TRP/ placebo dose was administered between 0630 and 0800 hours and the afternoon dose was given between 1400 and 1600 hours. A pilot study of SIB monkeys in which 50 and $100 \mathrm{mg} / \mathrm{kg}$ doses were used showed that the 100 $\mathrm{mg} / \mathrm{kg}$ was the lowest effective dose that increased CSF 5-HIAA concentrations and decreased self-biting. The 
TRP was added to the treat, according to our specifications, by BioServe ${ }^{\circledR}$. Each 5-gram treat contained $200 \mathrm{mg}$ of L-tryptophan and was scored into quarters for easy dosing.

\section{Behavioral Observations}

Behavioral sampling was conducted by one researcher who had more than 10 years of experience collecting nonhuman primate behavioral data. Data were obtained using the Observer ${ }^{\circledR}$ software package on an IBM laptop computer, which allowed the recording of the frequency and duration of each of 13 behaviors (see below). Each monkey was observed five times a week during the pretest and posttest periods and 10 times during the treatment period. Observations were randomized across the mornings and afternoons. Morning scoring occurred between 0700 and 1200 hours. Afternoon scoring sessions were completed between 1200 noon and 1600 hours. Each scoring session lasted 20 minutes, producing a total of 6 hours and 40 minutes of data for each subject. The following behaviors were recorded using an objectively defined scoring system: autoerotic, tactile/oral exploration of the environment, self-groom, passive, stereotyped locomotion, stereotypies (i.e., self-clasp, eye poke/salute, etc.), threats (i.e., directed toward the observer or other animals in the room), social behavior (i.e., rump or neck presenting, lipsmacking directed toward the observer or other animals in the room), fear (i.e., fear grimace toward observer or other animals in the room), contact enrichment, manipulate enrichment, self-biting, and SIB (i.e., spontaneous severe self-biting resulting in serious wounds that require clinical treatment). The veterinary care staff made daily rounds at regularly scheduled intervals to assess the physical condition of each animal in their facility, which ensured that injuries would be treated immediately if self-injury did occur.

\section{Physiological Data}

CSF was collected at the end of the 3rd week of TRP treatment. To allow sufficient time for TRP to be metabolized and act centrally, cisternal CSF samples were obtained 3 to 6 hours after dosing, between the hours of 1100 and 1300 . The animals were anesthetized with ketamine hydrochloride $(15 \mathrm{mg} / \mathrm{kg})$ for these procedures. We obtained 3 milliliters of CSF once each during the baseline, treatment, and posttest periods from each subject, using a 5-cc syringe with a 22-gauge needle following the procedures described by Higley et al. (1996). Samples were obtained in less than 30 minutes following anesthesia induction and immediately frozen in liquid nitrogen. Previous studies have shown that CSF monoamine concentrations are unaffected by ketamine if samples are collected within 30 minutes of ketamine injection (Brammer et al. 1987; Bacopoulos et al. 1979). CSF was stored at $-80 \mathrm{C}^{\circ}$ until assayed for 5-hydroxyindoleacetic acid (5-HIAA), homovanillic acid (HVA), and 3-methoxy 5-hydroxyphenylethyleneglycol (MHPG) by gas chromatography-mass spectrometry using deuterated internal standards (Polinsky et al. 1988). The coefficients of variation for the assays of the metabolites were 6,2 , and $5 \%$, respectively.

\section{Statistical Analyses}

Statistical analyses were computed using analysis of variance (ANOVA) and, where appropriate, Friedman's nonparametric analyses. Because there were an unequal number of behavioral samples taken during the three phases of the study (e.g., five scores during pre- and posttest and 10 during the TRP treatment), data were standardized by calculating the mean total duration (in seconds) per 20 minute scoring session for each of the three phases of the study. Preliminary analyses indicated that the variances for self-biting data were not homogeneous; thus, the nonparametric Friedman's test (Sokal and Rohlf 1987) was used to compare the means of self-biting across the study. A one-way repeated measure ANOVA was used to analyze all other data.

\section{RESULTS}

\section{Study One-SIB Monkeys}

During TRP treatment, the duration of self-biting was shorter than in the pre- and posttest periods (see Figure $1 ; \mathrm{df}=2$, Chi corrected for ties $=6.952, p=.03$ ). SIB did not occur during any phase of the study. TRP supplementation also markedly increased CSF 5- HIAA concentrations (See Figure 2) above pre- and posttest concentrations (See Table 1; F = 12.149, df = 2, $p=.0013$ ). CSF concentrations of MHPG and HVA during the treatment phase of the study were unaffected by TRP ( $p>$ .3-see Table 1). Except for the duration of self-biting, there were no other behavioral changes attributable to TRP supplementation $(p>.3)$.

\section{Study Two-Normal Monkeys}

Based upon the results in Study One, we examined the effect of TRP supplementation on the behavior and physiology of normal rhesus monkeys.

Subjects. Fourteen adult male rhesus monkeys were randomly selected for the study from the NIH Animal Center, Laboratory of Comparative Ethology colony. All monkeys were individually housed in stainless steel quad cages that provided each individual with $0.56 \mathrm{~m}^{2}$ of floor space. Prior values for the physiological measures in the study were available on these individuals 


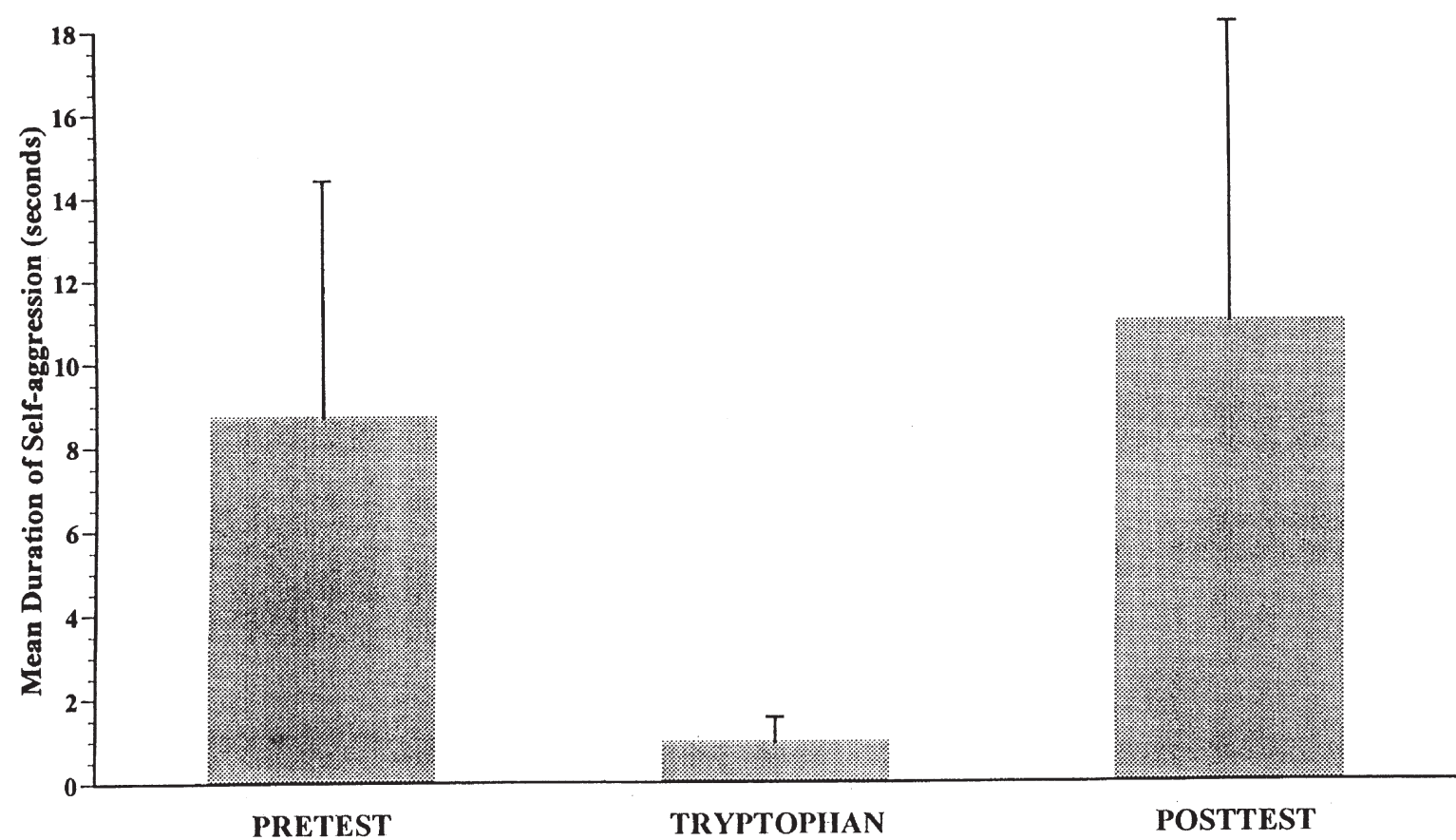

Figure 1. Mean duration and SD for self-biting during Study One; self-biting decreased during TRP treatment and increased during the posttest period.

from longitudinal data previously gathered (in some cases, since birth). Because appetite can be affected by central serotonin manipulation (Spring 1986), all monkeys were weighed weekly, and the number of biscuits that remained from the previous feeding was recorded prior to dispensing each monkey's next food ration.

Study Design. In Study One, marked changes in behavior occurred by the end of the 1st week of TRP treatment, and there were no differences between weeks 1 and 2. Therefore, the normal monkeys in Study Two were administered TRP for 1 week at each dosage level. There were four randomized treatments: placebo, 50, 100 , and $200 \mathrm{mg} / \mathrm{kg}$ TRP. Each treatment was administered for 1 week, and there was a 2 week placebo washout period between each treatment. TRP treats were administered orally twice a day, as described in Study One. The placebo treats provided during the placebo phases were identical to the TRP treats, lacking only in the TRP supplementation. Two subjects that refused the TRP treat were administered TRP in such alternative vehicles as pudding, marshmallow creme, yogurt, jam, or jelly. In these instances, the amount of vehicle was minimized, so as not to affect the transport of TRP across the blood-brain barrier due to competition for the large neutral amino acid carrier. Preliminary analyses of these two subjects' physiological data indicated that there was no differential effect of providing TRP in the alternative vehicles. At the end of the experiment, a dose of $400 \mathrm{mg} / \mathrm{kg}$ was administered to determine if a higher dose would result in physiological changes. Because most subjects refused to consume the $400 \mathrm{mg} / \mathrm{kg}$ when it was administered in the treat form, an alternative method of administration was manufactured. A grain-based nutritionally adequate diet comparable to the standard chow that the monkeys received was formulated and supplemented with additional TRP to the $400 \mathrm{mg} / \mathrm{kg}$ TRP dose. This diet was fed to the monkeys in lieu of their standard primate chow for one week. Of the 13 monkeys, only five consumed the diet.

Behavioral Observations. Each monkey was observed by two trained technicians who were blind to the treatment condition and the subject's CSF 5-HIAA concentrations. Interobserver reliability was tested using the Observer $^{\circledR}$ reliability test, and observers were in agreement greater than $95 \%$ of the time. Animals were observed in a random order 4 days per treatment period between the hours of 1100 and 1400 . Behaviors were recorded for 10 minutes per session on an IBM laptop equipped with the Observer ${ }^{\circledR}$ program. A total of 2 hours and 40 minutes of behavioral data were collected for each subject. The behaviors recorded for Study Two were the same as those described in Study One with two exceptions. The first was that eat and drink were divided into separate categories rather than being collapsed with tactile/oral exploration. In addition, sleep (defined as motionless with eyes closed for more than 15 seconds) was added because, although none of the SIB subjects slept during any of the observations in 


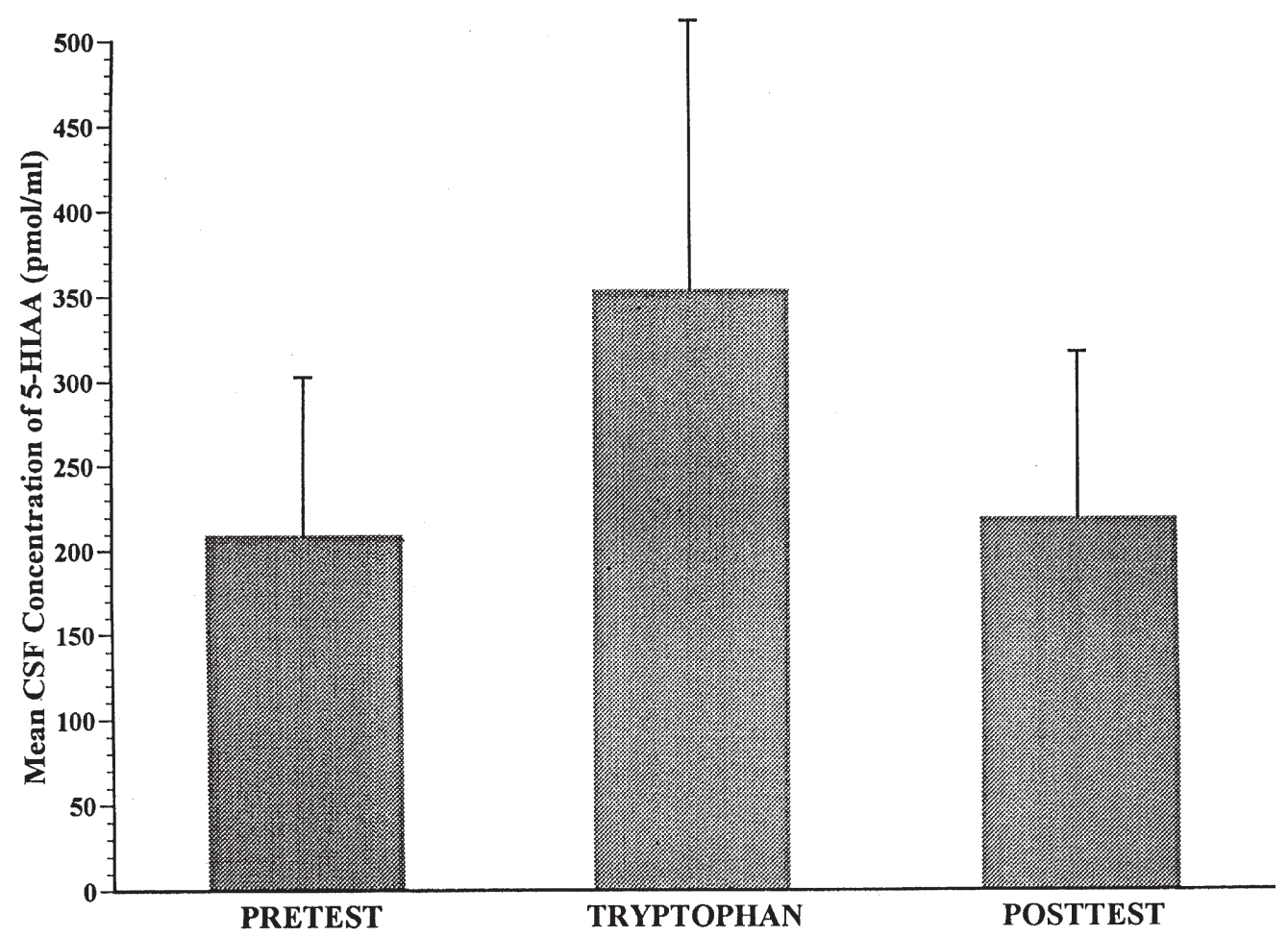

Figure 2. Mean and SD for CSF concentrations of 5-HIAA (picomoles/milliliter) for each of the phases of Study One.

Study One, the subjects in Study Two would be receiving twice the dose of TRP used in Study One, and drowsiness has been shown to increase following TRP augmentation (Steinberg et al. 1992; Olsen et al. 1994).

Physiological Data. Physiological data were collected once during each test phase in the same manner as in Study One, with one modification--in addition to collecting CSF, 7 milliliters of blood was obtained once on the last day of each treatment period. Blood was centrifuged, and the plasma collected from the chilled blood was frozen on liquid nitrogen and stored at $-80^{\circ} \mathrm{C}$ until it could be assayed for TRP concentrations using

Table 1. Means and Standard Deviations for CSF

Concentrations of 5-HIAA, MHPG, and HVA (in picomoles / milliliter) from SIB Monkeys $(n=7)$, Study One

\begin{tabular}{llcc}
\hline $\begin{array}{l}\text { Monoamine } \\
\text { metabolite }\end{array}$ & Phase of Study & Mean & $\begin{array}{c}\text { Standard } \\
\text { Deviation }\end{array}$ \\
\hline 5-HIAA & Pretest & 207.6 & 39.0 \\
& Tryptophan & $320.3^{a}$ & 83.4 \\
& Postteest & 202.2 & 39.1 \\
MHPG & Pretest & 86.9 & 11.1 \\
& Tryptophan & 85.1 & 12.2 \\
& Posttest & 86.3 & 18.8 \\
HVA & Pretest & 956.0 & 146.0 \\
& Tryptophan & 947.7 & 196.8 \\
& Posttest & 935.0 & 180.0 \\
\hline
\end{tabular}

${ }^{a}$ Notes significant difference between the 5-HIAA value during TRP treatment and the Pretest and Posttest values. high-performance liquid chromatography (HPLC) by Nicols Institute through Maryland Medical Metpath (coefficient of variation for the assay was 3.4\%).

Statistical Analyses. A two-way repeated measures ANOVA was used to compare each of the behaviors across the four phases. The within-group factors were treatment (placebo, 50, 100, or $200 \mathrm{mg} / \mathrm{kg}$ treatment) and day of treatment (Monday through Friday). The physiological data were analyzed using a one-way repeated measures ANOVA comparing the three treatment phases (baseline, TRP, posttest). Pearson product moment correlations were computed to examine correlations between TRP with CSF 5-HIAA, HVA, MHPG concentrations, and behavior. One subject was removed from the study during the second treatment period because of a physical illness unrelated to the experimental treatment. Analyses were completed on the remaining 13 animals. In addition, the baseline CSF 5-HIAA concentrations of the original 14 normal subjects in this study and the seven SIB monkeys from Study One were compared using a one-way ANOVA.

\section{RESULTS}

\section{Study Two-Normal Monkeys}

When compared to placebo, the subjects demonstrated no significant behavioral or physiological changes $(p>$ .3) during any of the three TRP doses (see Table 2). 
Table 2. Means and Standard Deviations for CSF Concentrations of 5-HIAA, MHPG, and HVA (in picomoles / milliliter) from Normal Rhesus Monkeys $(n=13)$, Study Two

\begin{tabular}{lccc}
\hline $\begin{array}{l}\text { Monamine } \\
\text { metabolite }\end{array}$ & Phase of Study & Mean & $\begin{array}{c}\text { Standard } \\
\text { Deviation }\end{array}$ \\
\hline 5 -HIAA & Placebo & 191.4 & 74.3 \\
& $50 \mathrm{mg} / \mathrm{kg}$ & 213.8 & 54.7 \\
& $100 \mathrm{mg} / \mathrm{kg}$ & 209.7 & 51.6 \\
& $200 \mathrm{mg} / \mathrm{kg}$ & 215.0 & 54.2 \\
MHPG & Placebo & 77.4 & 15.4 \\
& $50 \mathrm{mg} / \mathrm{kg}$ & 79.6 & 14.8 \\
& $100 \mathrm{mg} / \mathrm{kg}$ & 79.2 & 9.5 \\
& $200 \mathrm{mg} / \mathrm{kg}$ & 79.3 & 13.2 \\
$\mathrm{HVA}$ & $\mathrm{Placebo}$ & 1085.8 & 475.7 \\
& $50 \mathrm{mg} / \mathrm{kg}$ & 1078.4 & 481.9 \\
& $100 \mathrm{mg} / \mathrm{kg}$ & 1122.2 & 552.3 \\
& $200 \mathrm{mg} / \mathrm{kg}$ & 1080.6 & 342.3 \\
\hline
\end{tabular}

All subjects were administered three dosages 50, 100, and $200 \mathrm{mg} / \mathrm{kg}$; see the text for a full explanation.

When plasma was obtained from the five subjects that consumed the $400 \mathrm{mg} / \mathrm{kg}$ dose, after 3 days of that treatment, the plasma TRP concentrations were more than six times higher $($ mean $=381.0 \mathrm{mmol} / \mathrm{ml}$ ) than TRP concentrations obtained during placebo (mean = $59.4 \mathrm{mmol} / \mathrm{ml}$ ) and all other TRP treatment dosages $($ mean $=64 \mathrm{mmol} / \mathrm{ml})$ values.

When 5-HIAA concentrations in CSF obtained from normal and SIB monkeys during the pretest periods of both studies were compared, there was no difference between the concentration of 5-HIAA in SIB monkeys $($ mean $=207.6 \mathrm{pmol} / \mathrm{ml})$ and normal monkeys $($ mean $=$ $191.4 \mathrm{pmol} / \mathrm{ml})$.

\section{DISCUSSION}

In Study One, TRP increased CSF concentrations of 5-HIAA and reduced the rate of self-biting in rhesus monkeys that previously exhibited SIB. Although some self-biting was observed in the SIB subjects during the TRP treatment period, the behavior was not of sufficient severity to result in SIB, as measured by wounds requiring clinical treatment from the veterinary staff (i.e., suturing). Our results show that TRP seems to be an effective treatment for self-biting that may lead to SIB.

The SIB monkeys studied had average CSF 5-HIAA concentrations similar to those of normal monkeys, which is contrary to the findings of Kraemer et al. (1989), who reported high CSF 5-HIAA concentrations among monkeys exhibiting SIB that were socially deprived during rearing. Rearing history (mother- or peer-deprived) (Fittinghoff et al. 1974; Kraemer and Clarke 1990) can also affect the development of self-biting and its responsiveness to 5-HT (Kraemer and Clarke 1990). Information on the rearing history of our
SIB subjects was not available; thus, it is possible that the discrepancy between the findings presented here and those of Kraemer and Clarke (1990) may be attributable to differences in age or early rearing histories of the subjects. SIB and self-biting are not limited to monkeys that have experienced social isolation early in life (Erwin et al. 1973; see Capitanio 1986 for a review). For example, during the past decade, there have been three cases of spontaneous SIB occurring in monkeys born in our laboratory, and all three had been reared in social groups.

Whereas humans with suicidal tendencies have been reported to have low CSF concentrations of 5-HIAA (Brown et al. 1982a, b; Asberg et al. 1987), the CSF 5-HIAA concentrations of SIB monkeys were not especially low, and some of the normal monkeys in Study Two with no history of SIB had markedly low CSF 5-HIAA concentrations. Therefore, in general, SIB in rhesus monkeys would not seem to provide an appropriate model for the human suicidal behavior related to low CNS serotonin functioning.

The CSF catecholamine concentrations were not related to the severity of SIB and were unaffected by TRP treatment, but the sensitivity of the SIB monkeys to stimulation by means of serotonergic augmentation (TRP) was evident in both their behavior and physiology. Although the long-term outcome for most of the SIB monkeys included in the present study is unknown, we were able to complete physiological follow-ups on two of the monkeys 8 months posttreatment. CSF samples taken at that follow-up were assayed for 5-HIAA concentrations, and the values did not differ from those taken during the pretest period. To date, only one of the seven monkeys in Study One has inflicted self-injury serious enough to require veterinary treatment since the end of the study, and that injury occurred 2 months after completion of the study. One advantage of TRP treatment of self-biting in monkeys is that it can be readily treated in this manner with minimal expense and labor.

Contrary to results from studies of vervet monkeys (Raleigh et al. 1983 and personal communication 1992), most of our subjects readily ate the TRP supplements at doses less than $400 \mathrm{mg} / \mathrm{kg}$. TRP supplementation of normal rhesus monkeys in Study Two did not result in increases in plasma TRP concentrations or 5-HIAA concentrations. Although a dose of $400 \mathrm{mg} / \mathrm{kg}$ twice a day did increase plasma TRP concentrations, the dose was voluntarily consumed by only a few of the normal monkeys.

\section{SUMMARY}

Oral TRP supplements were effective in the treatment of self-biting in rhesus monkeys. We found that self-biting decreased and CSF 5-HIAA concentrations increased when monkeys exhibiting this behavior were fed the 
TRP supplements. Comparable TRP supplements had no apparent behavioral or biochemical effects on central serotonin turnover rate in nonSIB monkeys.

\section{REFERENCES}

Asberg M, Schalling D, Traskman-Bendz L, Wagner A (1987): Psychobiology of suicide, impulsivity, and related phenomena. In Metzer HY (ed), Psychopharmacology: The Third Generation of Progress. New York, Raven, pp 665-668

Bacopoulos BG, Redmond DE, Roth RH (1979): Serotonin and dopamine metabolites in brain regions and cerebrospinal fluid of a primate species: Effects of ketamine and fluphenazine. J Neurochem 32:1215-1218

Bayne K, Dexter S, Woodman D, Evans C (1995): Nonhuman primate wounding prevalence: A retrospective analysis. Lab Animal 24:40-44

Brammer GL, Raleigh MJ, McGuire MT, Rubinstein EH (1987): Comparison of ketamine, physical restraint, halothane, and pentobarbital: Lack of influence on serotonergic measures in monkeys and rats. Neuropharmacology 26:1615-1621

Brown GL, Ebert MH, Goyer PF, Jimerson DC, Klien WJ, Bunney WE, Goodwin FK (1982a): Aggression, suicide and serotonin: Relationship to csf amine metabolites. Amer J Psychiat 139:741-746

Brown GL, Goodwin FK, Bunney WEJ (1982b): Human aggression and suicide and their relationship to neuropsychiatric diagnoses and serotonin metabolism. Adv Biochem Psychopharmacol 34:287-307

Brown GL, Goodwin FK, Ballinger JC, Goyer PF, Major LT (1979): Aggression in humans correlates with cerebrospinal fluid amine metabolites. Psychiatry Res 1:131-139

Capitanio J (1986): Behavioral pathology. In Mitchell G, Erwin J (eds), Comparative Primate Biology, vol 2A, Behavior, Conservation and Ecology. New York, Alan R. Liss, pp 411-454

Chamberlain B, Ervin FR, Pihl RO, Young SN (1987): The effect of raising and lowering tryptophan levels on aggression in vervet monkeys. Pharmacol Biochem Behav 28:503-510

Cleare AJ, Bond AJ (1995): The effect of tryptophan depletion and enhancement on subjective and behavioral aggression in normal male subjects. Psychopharmacology 118:72-81

Erwin J, Mitchell G, Maple T (1973): Abnormal behavior in nonisolate-reared rhesus monkeys. Psych Rep 33:515-523

Favazza AR, Rosenthal RJ (1993): Diagnostic issues in selfmutilation. Hosp Comm Psychiat 44:134-140

Fittinghoff NA, Lindburg DG, Gomber J, Mitchell G (1974): Consistency and variability in the behavior of mature, isolation-reared, male rhesus macaques. Primates 15:111139

Gillman PK, Bartlett JB, Bridges PK, Hunt A, Patel AJ, Kantamaneni BD, Curzon G (1981): Indolic substances in plasma, cerebrospinal fluid, and frontal cortex of human subjects infused with saline or tryptophan. J Neurochem 37:410-417
Harris JC (1995): Developmental Neuropsychiatry (vol II): Assessment, Diagnosis, and Treatment of Developmental Disorders. New York, Oxford University Press

Higley JD, King ST, Hasert MF, Champoux MB, Suomi SJ, Linnoila M (1996): Stability of interindividual differences in serotonin function and its relationship to aggressive wounding and competent social behavior in rhesus females. Neuropsychopharmacology 14:67-76

Huether G, Hajak G, Reimer A, Poeggeler B, Blomer M, Rodenbeck A, Rather E (1992): The metabolic fate of infused L-tryptophan in men: Possible clinical implications of the accumulation of circulating tryptophan and tryptophan metabolites. Psychopharmacology 109:422432

Jones IH, Barraclough BM (1978): Automutilation in animals and its relevance to self-injury in man. Acta Psychiatr Scand 58:40-47

Kraemer GW, Ebert MH, Schmidt KE, McKinney WT (1989): A longitudinal study of the effect of different social rearing conditions on cerebrospinal fluid norepinephrine and biogenic amine metabolites in rhesus monkeys. Neuropsychopharmacology 2:175-189

Kraemer GW, Clarke AS (1990): The behavioral neurobiology of self-injurious behavior in rhesus monkeys. Prog Neuropsychopharmacol Biol Psychiat 14:S141-168

Lindgren T, Kantak KM (1987): Effects of serotonin receptor agonists and antagonists on offensive aggression in mice. Aggress Behav 13:87-96

Linnoila M, Virkkunen M, Scheinin M, Nuutilia A, Rimon R, Goodwin FK (1983): Low cerebrospinal fluid 5-hydroxyindoleacetic acid concentration differentiates impulsive from nonimpulsive violent behavior. Life Sci 33:26092614

Lopez-Ibor JJ, Saiz-Ruiz J, Perez de los Cobos JC (1985): Biological correlations of suicide and aggressivity in major depressions (with melancholia): 5-Hydroxyindoleacetic acid and cortisol in cerebrospinal fluid, dexamethasone suppression test, and therapeutic response to 5- hydroxytryptophan. Neuropsychobiology 14:67-74

Luchins DL (1990): A review of pharmacological agents for self-injurious behavior. Prog Psychopharmacol Biol Psychiat 14:S169-179

Mench JA, Shea-Moore MM (1995): Moods, minds and molecules: The neurochemistry of social behavior. Appl Anim Behav Sci 44:99-118

Meyer-Holzapfel M (1968): Abnormal behavior in zoo animals. In Fox FW (ed), Abnormal Behavior in Animals. Saunders, Philadelphia, pp 476-503

Olivier B, Tulp MM, Mos J (1991): Serotonergic receptors in anxiety and aggression: Evidence from animal pharmacology. Hum Psychopharmacol 6:573-578

Olsen OE, Neckelmann D, Ursin R (1994): Diurnal differences in L-tryptophan, sleep, and temperature effects in the rat. Behav Brain Res 65:195-203

Osman OT, Loschen EL (1992): Self-injurious behavior in the developmentally disabled: Pharmacologic treatment. Psychopharm Bull 28:439-449

Pardridge WM (1977): Regulation of amino acid availability to the brain. In Wurtman RJ, Wurtman JJ (eds), Nutrition and the Brain. New York, Raven, pp 141-204 
Polinsky TJ, Brown RT, Burns RS, Harvey-White J, Kopin IF (1988): Low lumbar CSF levels of homovanillic acid and 5-hydroxyindoleacetic acid in multiple system atrophy with autonomic failure. J Neurol Neurosurg Psychiat 51:914-919

Raleigh MJ, Brammer GL, Yuwiler A, McGuire MT (1983): Male dominance, serotonergic systems, and the behavioral and physiological effects of drugs in vervet monkeys (Cercopithecus aethiops). In Miczek KA (ed), Ethopharmacology: Primate Models of Neuropsychiatric Disorders. New York, A. R. Liss, pp 185-197

Raleigh MJ (1987): Differential behavioral effects of tryptophan and 5-hydroxytryptophan in vervet monkeys: Influence of catecholaminergic systems. Psychopharmacology 93:44-50

Roy A, Adinoff B, Linnoila M (1988): Acting out hostility in normal volunteers: Negative correlation with levels of 5-HIAA in cerebrospinal fluid. Psychiat Res 24:187-194

Roy A, Linnoila M (1988): Suicidal behavior, impulsiveness, and serotonin. Acta Psychiatr Scand 78:529-535

Shea MM, Mench JA, Thomas OP (1990): The effect of dietary tryptophan on aggressive behavior in developing and mature broiler breeder males. Poultry Sci 69:1664-1666

Shea MM, Douglass LW, Mench JA (1991): The interaction of dominance status and supplemental tryptophan on aggression in Gallus domesticus males. Pharmacol Biochem Behav 38:587-591

Sokal R, Rohlf J (1987): Introduction to biostatistics, 2nd ed. New York, WH Freeman and Company

Spring B (1986): Effects of foods and nutrients on the behavior of normal individuals. In Wurtman RJ and Wurtman JJ (eds), Nutrition and the Brain, NY, pp 1-47

Steinberg LA, O'Connell NC, Hatch TF, Picciano NF, Birch LL (1992): Tryptophan intake influences infants' sleep latency. J Nutr 122:1781-1791

Tinklepaugh O (1928): The self mutilation of a male macacus rhesus monkey. J Mammal 293-300

Valzelli L, Bernasconi S (1979): Aggressiveness by isolation and brain 5-HT turnover changes in different strains of mice. Neuropsychobiology 5:129-135

Walsh BW, Rosen PM (1988): Self-mutilation: Theory, research, and treatment. New York, Guilford

Winchel RR, Stanely M (1991): Self-injurious behavior: A review of the behavior and biology of self-mutilation. Am J Psychiat 148:306-315

Young SN, Ervin FR, Pihl RO, Finn P (1989): Biochemical aspects of tryptophan depletion in primates. Psychopharmacology 98:508-511 